\title{
Editorial
}

\section{A passion for Chironomidae}

Halfway through my $82^{\text {nd }}$ year I hope that our readers will bear with my reminiscences and observations. My mother reports that my first encounter with invertebrates was when I presented her with a live scorpion on a cushion, saying 'Look!' I cannot recollect what my mother's reaction was, but she had only recently settled in South India and had developed a deep mistrust of legless vertebrates in particular and invertebrates in general. Whatever it was, it didn't stop me looking. By 8 I was chasing butterflies around the compound with a net my mother made me from an old tennis racket. This turned into a scientific enterprise when my father found a book on Indian butterflies; I pored over the descriptions and memorized their scientific names and searched for species I hadn't previously seen as distinct. The butterflies were placed in envelopes, labelled with their binomina and full data. The collection was stored in an old tin suitcase and covered with Gammexane to keep the ants at bay while away at boarding school. Boarding school was in the jungled Palni Hills at 2000 metres. It was a paradise for a budding invertebratologist: the jungles surrounding the school in those days not only harboured elephant and tigers, but teemed with insects - the large beetles were the best fun: we kept the biggest stag beetles we could find in our desks during class time and would fight them during breaks. I would get up early in the morning and sneak out of the school grounds against regulations to shin up the lamp pole in the centre of the Seven Ways Roundabout to find what moths had been attracted overnight (half a century later I visited my old school - the lamp post has gone.). I even contemplated joining the Franciscans, primarily because of their interest in the local plants and animals rather than their ascetic lifestyle; the museum at the monastery is still there today. So it was that when the family moved to England at age 14 I was already a committed entomologist. My first headmaster in England when interviewing me asked what I saw as my future career I said 'An entomologist', to which he replied, 'Well, it's a good hobby'; I replied, 'No Sir, that is to be my life's work'. He was right in a way, but here I am still an entomologist, an amateur, yes, and as such have suffered for lack of funding, but at liberty to follow my interests unrestricted.

The butterflies in England were a disappointment: small in size and few in species. I turned to moths, but by the time I went to university I had switched to beetles; what they lacked in size, they made up for with great diversity. However, that was to change for good after I left university and took up a biology teaching post at a secondary school in the East Anglian Fens, absolutely flat, farmed to the roadside verges and crisscrossed with ditches and drains. Undeterred I took to investigating the beetles of the various waterways, but water beetles in Britain had been extensively researched and I discovered an insect group that was rich in numbers and in species, and little researched. This was the challenge I was looking for.

I started by collecting the adults and used the Royal Entomological Society's Handbook for Chironomidae, by Coe. I soon got into trouble! So I sent Paul Freeman at the British Museum Natural History a couple of specimens I was having particular difficulty with. He sent them back, named. This prompted me to send him a box of about 30 specimens, which I received back by return with a note telling me to visit the Museum where I would be given facilities to name them myself, having access to the collections, the library and Paul Freeman's guidance. After that beetles had only cursory attention: I was hooked! Strange; Lars Brundin told me he too had come to Chironomidae via the Coleoptera. I threw myself into the literature on Chironomidae and discovered that the pupal exuviae were identifiable to species: what a great way of finding what species inhabited a ditch, pond, lake, stream or river by just collecting the floating pupal exuviae! However, many of the specimens I collected were not identifiable using the published keys and descriptions of Thienemann, Lenz, Pagast and others. A more comprehensive key was needed, which I set out to produce, through rearing larvae to adult. The technique I developed used plastic boxes $10 \times 7 \times 4 \mathrm{~cm}$ with transparent lids, of the sort used to sell cut comb honey. $4 \mathrm{~mm}$ depth of tap water ensured a large surface to volume, which, together with the large volume of air enclosed, allowed sufficient oxygenation of the water for over a week without removing the lid. The pabulum I used was the mulm (mainly fish excrement) from the bottom of a wellstocked tropical fish tank, which I sterilized with boiling water before adding to the water; only a small squirt from a pipette provides sufficient food for the completion of development. 350 containers, each with 1 larva were stacked on shelves in the utility room and checked morning and night for emerged adults, or dead pharate adults. Any adults were pooted out and the pupal exuviae and dead pharate adults (and when obvious, the larval exuviae) were transferred to vials containing $70 \%$ isopropanol until mounting on microscope slides in Euparal, the pupal exuviae on the same slide as the adult. The containers were washed 
and restocked with a single larva and replaced on the shelf. Species from high mountain streams to lowland lakes generally completed their development in these containers at about $20^{\circ} \mathrm{C}$.

This was continued for seven years as part of an external Ph.D. carried out in my spare time as a school teacher. From the Ph.D. 'A key to the Pupal Exuviae of British Chironomidae' was compiled. Not being part of the establishment, publication was rejected, so I borrowed money to publish it myself (1984). I sold the books at cost price and the 200 were all sold, so I got my money back from the venture. At the International Symposium in Bergen (1985), Ole Sæther invited the delegates to a soirée at his home. I was standing, glass in hand, chatting, when approached by Frieder Reiss, who said 'Come'. When Frieder said come, you come! I followed him to the far end of the room where in the corner was seated 'Sepp' Fittkau . Pointing to a chair opposite Fittkau, Frieder said 'Sit', so I sat. 'Dr. Fittkau and I think you should produce a key

like the one you produced for Britain for the West Palaearctic.' I responded by excusing myself: I was a full time school teacher, I hadn't the resources to travel the Continent.... I was stopped 'You must do it', said Frieder. 'You will come to Munich where the collection will be made available to you and space for you to work. There is no funding [What's new?] but you must do it'. So that led to three glorious visits to Munich, where Fittkau vacated his room for me to work in and Frieder supplied me with tray after tray of slides to work on. I was loaned a key to the museum, arrived at 8 and left at 8 each day. I was allowed to borrow specimens so that I could continue work at home. The result was 'A Key to Pupal Exuviae of West Palaearctic Chironomidae' (1991). Once again, I found I had to publish it myself - an extension of my house mortgage was arranged to fund it. In 2001 Henk Visser of the Biodiversity Centre of ETI in Amsterdam contacted me with the offer of turning the 1991 Key into a CD ROM. I agreed, providing we could update it. To this he agreed and the CD ROM was published in 2003. Since then the upgrade of Microsoft windows has rendered it inoperable, but an IT friend has managed to produce a copy that works for both Microsoft and Mac.

In 1995 I had the opportunity to summarize my knowledge of the pupal stage of the Chironomidae in 'The Chironomidae', edited by Armitage, Cranston and Pinder. In 1997 or thereabouts I was asked by the Freshwater Biological Association whether I would update the 'Key to Chironomidae (Adults)' (1978) as it was then out of print and out of date, in collaboration with the author of that work, Clive Pinder. I had, of course, a wide knowledge of the adult males, because the identity of pupal exuviae required identification of the adults reared. This took ten years and was published in 2007. It took that long, because there were frequent additions to the British fauna and nomenclatural changes that required rejigging the keys that had been developed.

Shortly after the publication of the West Palaearctic key I was contacted by Bill Coffman asking if I would turn his massive collection of pupal exuviae into a key for Nearctic species. This resulted in three visits to Pittsburgh and Pymatuning, where we trawled his collections for distinct (and often, not so distinct) morphotypes, with sporadic field excursions to satisfy a basic need of two inveterate collectors! I was invited to Minnesota by Len Ferrington to trawl his collection as well. I set about the Nearctic key with a will, but the momentum dropped when, sadly, Bill died prematurely of pancreatic cancer in 2013. I owe it to Bill and my other Nearctic colleagues to finish this work, if spared, and at present it is making good progress.

I live in Northern Ireland, a watery land with lots of lovely midges. I have just completed a long-term phenology/biodiversity project here, which, I suppose, may never be published. It's completion leaves me free to concentrate on the Nearctic key. I continue to be blessed with a steady hand and reasonable eyesight, enjoy collecting (you can't beat water for enhancing the visual natural environment), looking (yes, still looking!) at these fascinating beasts, informing others through publications and drawing the diagrams to accompany those submissions (I cannot agree more with Alyssa Anderson's views on the value of line drawings (CHIRONOMUS editorial 2013)).

I value the acquaintance of many colleague-friends across the world. COVID-19 and progressive age related physical deterioration willing, I shall see you all in Japan in one and a half year's time. I look forward to that!

Peter H. Langton

16 Irish Society Court, Coleraine, Co. Londonderry, Northern Ireland BT52 1GX.

E-mail: langtonph@gmail.com 